\title{
Asymmetry: The Foundation of Information. By Scott Muller. Springer: Berlin. 2007. VIII, 165 p. 33 illus., Hardcover. CHF 139.50. ISBN: 978-3-540-69883-8
}

\section{Shu-Kun Lin}

Molecular Diversity Preservation International (MDPI), Matthaeusstrasse 11, CH-4057 Basel, Switzerland; Tel. (+41) 79322 3379; Fax: (+41) 61302 8918; E-mail: lin@mdpi.org;

http://www.mdpi.org/lin

Received: 25 March 2008 / Published: 13 June 2008

Normally a religious book should be read at least 100 times; a philosophy book 10 times and a science monograph should be read carefully at least once before you can claim that you have read the book and understand something. However, with the information explosion, nowadays, people do not have enough time to read even one time from cover to cover, even for books prepared by philosophers. That is why wise writers make the book title longer and longer and the main statements of conclusions are simply given in the title. I guess some people may claim that they have read the book already even though actually they have only glanced at the title, or perhaps the table of contents. This book [1] is prepared in such a way that perhaps the author did not really expect anyone to read it carefully. The reference list has more than one style. The word "distinguishability" was misspelled on page 22 once and the wrong word even appeared in the Index as a separate entry.

This book is based on the $\mathrm{PhD}$ thesis completed in 2004 with John Collier as the cosupervisor, at the Philosophy and Religious Studies section of University of Newcastle, Australia. The main idea that "asymmetry is the foundation of information" as can be seen in the title might be derived from John Collier's statement that "information originates in symmetry breaking” and "causation is the transfer of information", which appeared as article titles of two papers cited in this book. Interested readers may directly read these two papers, available at John's homepage [2]. I was attracted by the title and the table of contents because asymmetry-information-distinguishability relationship and entropysymmetry-indistinguishability relationship was presented in my papers published since 1996. I conceived the idea of higher symmetry-higher entropy relationship and the related conclusions because of my doubt about the validity of the entropy theory of Prigogine's school of thermodynamics [3,4] and based on my resolution of the Gibbs paradox and new entropy-similarity relationship [5]. The keyword Gibbs paradox also appeared in the table of contents. 
This book belongs to the book series The Frontiers Collection, edited by A.C. Elitzur, M.P. Silverman, J. Tuszynski, R. Vaas and H.D. Zeh. I will read another book in this series authored by Joe Rosen "Symmetry Rules: How Science and Nature Are Founded on Symmetry (The Frontiers Collection). Readers interested in symmetry-entropy and asymmetry-information issues are encouraged to read Joe's books [6,7] also.

Acknowledgments: The author kindly sent me a pdf version of the book. I am grateful to my long time colleague Dr. Derek McPhee for his collaboration and assistance.

\section{References and Notes}

1. This book's homepage: http://www.springer.com/computer/foundations/book/978-3-540-69883-8.

2. http://www.ukzn.ac.za/undphil/collier/

3. Lin, S.-K. Diversity and entropy. Entropy 1999, 1, 1-3.

4. Lin, S.-K. Book Review: Modern Thermodynamics: From Heat Engines to Dissipative Structures. By Dilip Kondepudi (Wake Forest University) and Ilya Prigogine (University of Texas at Austin). Wiley: Chichester, UK. 1998. 486pp. £24.95. ISBN 0-471-97394-7. Entropy 1999, 1, 148-149.

5. Lin, S.-K. Gibbs Paradox and the Concepts of Information, Symmetry, Similarity and Their Relationship. Entropy 2008, 10, 1-5. arXiv:0803.2571.

6 Lin, S.-K. Book Review: Symmetry in Science: An Introduction to the General Theory. By Joseph Rosen. Springer Verlag: New York. 1996. 234pp. \$29.95. ISBN 0-387-94836-8. Entropy 1999, 1, 53-54.

7. Rosen, J. Comment: The Symmetry Principle. Entropy 2005, 7, 308-313.

(C) 2008 by the authors; licensee Molecular Diversity Preservation International, Basel, Switzerland. This article is an open-access article distributed under the terms and conditions of the Creative Commons Attribution license (http://creativecommons.org/licenses/by/3.0/). 